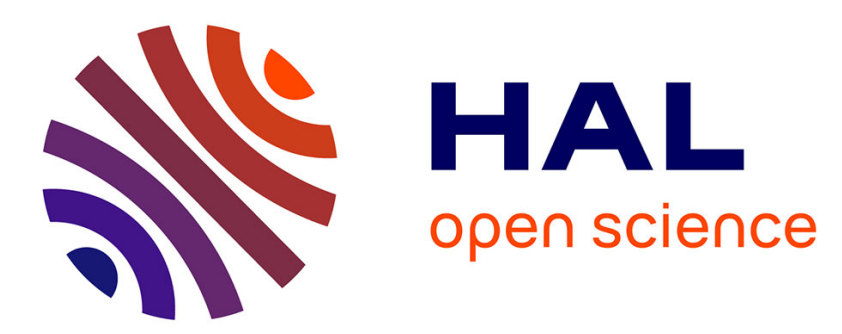

\title{
Implicit Discrete Element Analysis of a Masonry Cupola Under Seismic Loads
}

\author{
Ali Rafiee, Marc Vinches
}

\section{To cite this version:}

Ali Rafiee, Marc Vinches. Implicit Discrete Element Analysis of a Masonry Cupola Under Seismic Loads. International Journal of Civil Engineering, 2016, 14 (6A), pp.357-367. 10.1007/s40999-0160035-0 . hal-02906434

\section{HAL Id: hal-02906434 \\ https://hal.science/hal-02906434}

Submitted on 26 May 2021

HAL is a multi-disciplinary open access archive for the deposit and dissemination of scientific research documents, whether they are published or not. The documents may come from teaching and research institutions in France or abroad, or from public or private research centers.
L'archive ouverte pluridisciplinaire HAL, est destinée au dépôt et à la diffusion de documents scientifiques de niveau recherche, publiés ou non, émanant des établissements d'enseignement et de recherche français ou étrangers, des laboratoires publics ou privés. 


\title{
Implicit Discrete Element Analysis of a Masonry Cupola Under Seismic Loads
}

\author{
Ali Rafiee ${ }^{1} \cdot$ Marc Vinches $^{2}$
}

\begin{abstract}
In the current study, the dynamic mechanical behaviour of a masonry cupola composed of non-convex discrete elements is investigated. This cupola is designed in innovative and modern ways and was recently constructed with stone blocks in the south of France. The necessity of applying an accurate numerical modelling method being able to take into account the real geometry of each nonconvex block is also presented and discussed. The stability state of this masonry structure, by considering the different levels of seismic loads is studied. In addition, the effects of changes in the contact condition between blocks, or the blocks and the structure foundation, are comprehensively investigated.
\end{abstract}

Keywords Numerical model · Masonry structure - Seismic loads · Discrete elements · Non-smooth contact dynamics

\section{Introduction}

The development of numerical tools in the field of structural analysis, over the last few years, has enabled researchers to establish diverse approaches for the numerical modelling of masonry structures. Nevertheless, the analysis of the mechanical behaviour of masonry structures remains challenging due to the influence of numerous factors such as taking into account their discontinuous nature. The

Ali Rafiee

ali_rafiee@znu.ac.ir

1 Mining Engineering Department, University of Zanjan, Zanjan, Iran

2 Laboratoire du Génie de l'Environnement Industriel, Ecole des Mines d'Alès, 30319 ALES CEDEX, Alès, France limitations of experimental and analytical modelling when considering representative buildings increase the necessity of numerical modelling tools dedicated to masonry structures. Discrete element methods are inherently able to capture the discontinuous nature of masonry structures and allow either static or fully dynamic analyses with large displacements. Several modelling approaches of masonry structures (based on continuous or discontinuous modelling) are currently under development by several research teams (Rafiee and Vinches [1] and Idris et al. [2]). The discrete element modelling is widely used in particular for assessing the mechanical behaviour of historical masonry structures, or after the determination of their vulnerability to utilise reinforcement and restoration techniques.

In the present paper, our objective is to study the stability and collapse mechanisms of a new stone masonry construction subjected to static and seismic loadings. A masonry cupola is investigated with the discrete element method using the open platform LMGC90 [3], which is mainly based on the non-smooth contact dynamics (NSCD) method. This software allows to model divided materials, made of rigid or deformable bodies, with complex mechanical behaviour (elasto-plastic, damaged materials) or interactions (frictional and cohesive contacts).

The NSCD method proposed by Moreau [4-6], Jean [7-10], Jean and Moreau [11] is used in the current study; therefore, major part of the introduction is dedicated to introduce briefly this method. This method is a discrete element method (DEM) dedicated to the simulation of divided materials [12]. It emerged from the mathematical framework of non-smooth dynamics and subsequent algorithmic developments. The "nonsmoothness" arises from various aspects such at velocity jumps due to contact and friction.

The NSCD method has shown its efficiency particularly in the simulation of granular media [13]. The method has 
also been applied to the mechanical analysis of masonry structures [1, 14-16]. Cundall was the first to propose a numerical tool, in granular media where large collections of bodies are encountered, considering particles as rigid bodies with contacts governed by a compliant model [17]. The contacts between the particles in a model are assumed to obey a viscoelastic behaviour in which the local strain variables are the relative particle displacements and velocities [18]. It relies on an explicit time integration scheme of the equations of motion which implies to deal with the small time and space scales involved in contact interactions [12].

Considering the NSCD method, such small scales are taken into account in contact laws (possibly stiff) which necessitate a non-smooth formulation of particle dynamics [12]. In other words, the NSCD method is distinguishable from customary DEM methods using an implicit time integration scheme and non-regularized interaction law [15]. For example, the contact laws are expressed as "complementarity" relations between the contact force and the relative velocity without introducing artificial penalization parameters or damping. Friction is modelled through Coulomb's law. NSCD method does not involve small interpenetrations between particles as with a customary DEM method, and whatever the time step the method is unconditionally stable due to the implicit time integration scheme [19]. A more detailed discussion on the NSCD method and the mathematical formulation used in this method can be found in [4-6, 8, 9, 11]. A brief explanation of the basic formulation of the NSCD method can be obtained in [15]. The LMGC90 software is mainly based on the NSCD method [3]. All the results presented thereafter were obtained using this code. The valuable feature of LMGC90 is its large range of contact laws already implemented and its ability to manage various object shapes [19]. All above mentioned studies and also previous scientific works of the authors can show the capacities of the NSCD method and also the LMGC90 code for modelling complex masonry structures. The current study tries to present the obtained results for a recently constructed masonry structure and to highlight the importance of the input geometry in the final conclusion. The validity comparison of using the NSCD method for masonry structure is previously performed for large number of basic and academic masonry structures by the well-known researchers in this field and also by the authors of this study.

\section{The Cupola of Junas}

The structure was designed by the French association of "Compagnons Passants Tailleurs de Pierre". This building was designed in the framework of the meeting of stone masons from France and Europe in Junas, a village from the Gard department, in southern France. This association, with this cultural project aims at a revival of the relationship between architects, engineers and stone craftsmen. The structure is a $8 \mathrm{~m}$ diameter half-sphere of stone, opened at its top with a $1 \mathrm{~m}$ diameter hole, and at its base, resting only five pillars $2 \mathrm{~m}$ high, $0.7 \mathrm{~m}$ wide and $0.4 \mathrm{~m}$ thick (Fig. 1). These structures aims to symbolise knowledge sharing (different professions contribute to this experience) and universality (the half-sphere represents the Earth and the five pillars the five continents) (Fig. 1a).

The stones used in this structure are limestones and sandstones from different quarries in the south of France (Fig. 1b). For the sake of simplicity, only one type of stone with its specific weight and contact properties is considered in the following numerical study.

Before the construction of this cupola, its mechanical behaviour was investigated in two phases using the discrete element method. It should be also noted that the smallscale structure was tested by this association, and that structure was mechanically stable without any reinforcement system. It can be said that the main objective of this study is to present the results and conclusions that can be yielded from the effect of geometrical simplification in numerical modelling for this type of masonry structure. In a first step, this masonry structure was studied without considering its real geometry and the effect of this determinative parameter was neglected. Because of restrictions that existed 10 years ago in many discrete element codes to take into account the masonry blocks with non-convex boundaries, this structure was studied by simplifying the non-convex blocks into convex ones. This type of simplification for masonry structure modelling did lead to erroneous results. In this study, the results obtained for this structure are presented separately and compared for both the geometrically simplified and the non-simplified models.

\section{Preliminary Study Using a Simplified Geometry of the Cupola}

Stability studies of this stone structure were carried out by Chetouane [20] and Perales [21]. In both studies, the results show that the investigated structure is not stable. Figure 2 shows the geometry of cupola used in their studies [21]. Chetouane studied this structure with the dry friction law of Coulomb without cohesion [20]. Figure 3a shows a result obtained considering a dry friction coefficient of 0.7 between the blocks, 0.9 between the blocks and the structure foundation, and a stone block density of $2000 \mathrm{~kg} / \mathrm{m}^{3}$ after $0.5 \mathrm{~s}$ of simulation. As can be observed, the simulations were made using a coarse geometrical description considering convex blocks, which converts the face-face 

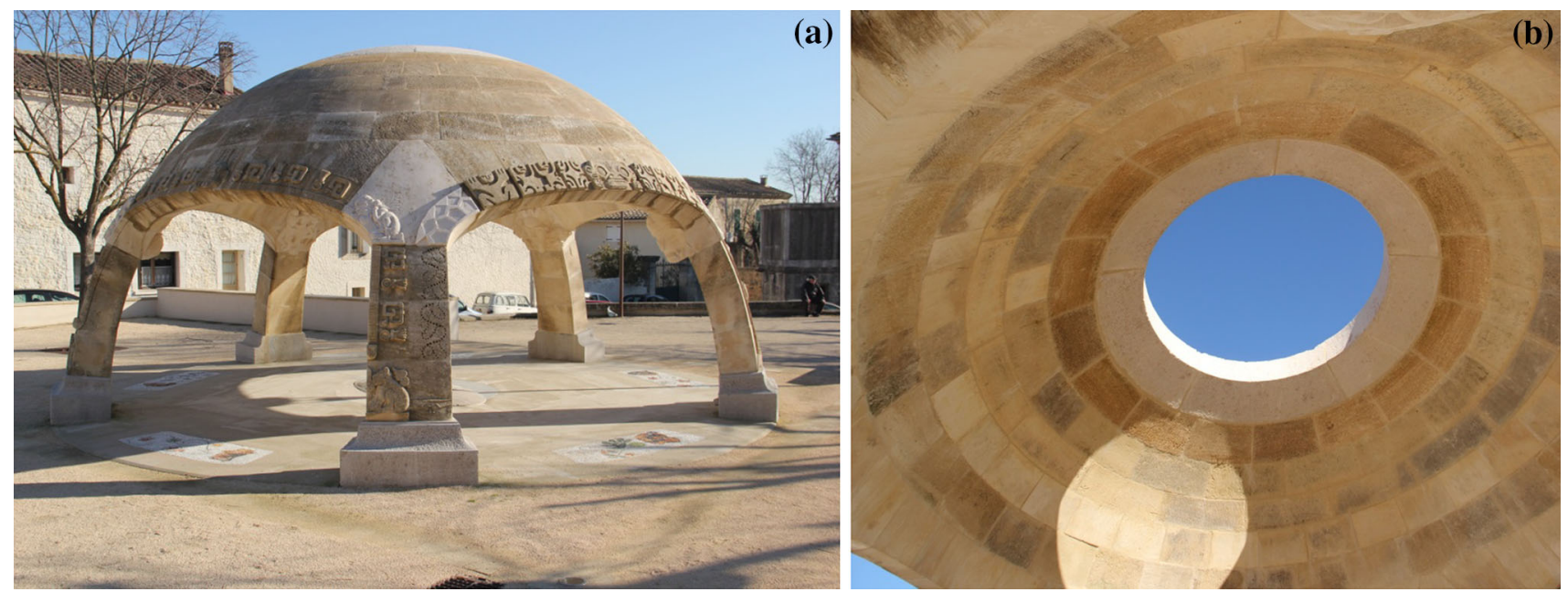

Fig. 1 The cupola of Junas. a Final geometry of the cupola, b view from inside the structure, showing different types of stone used in its construction

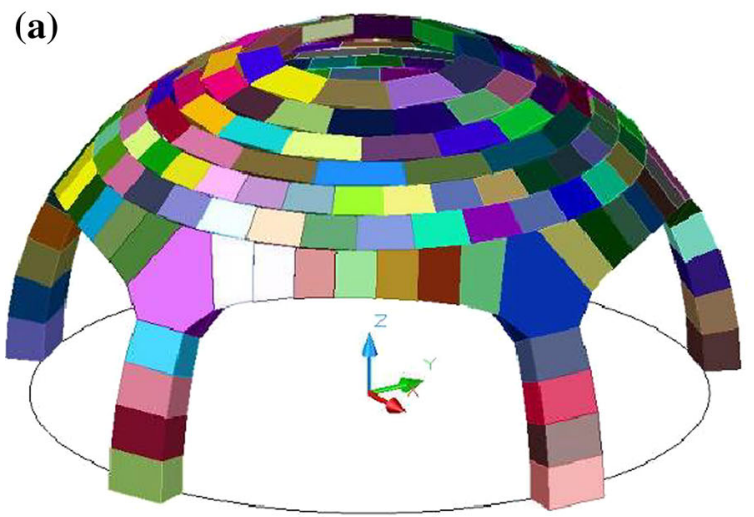

(b)

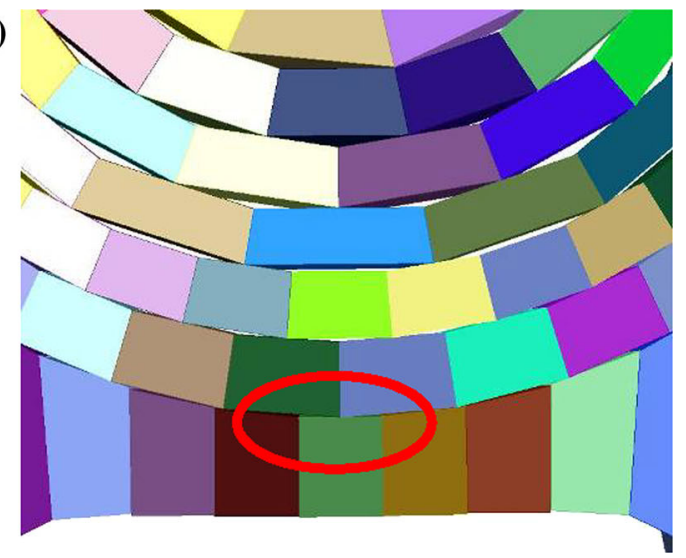

Fig. 2 a Geometry of the cupola used in previous studies [21], b close-up view of the structure
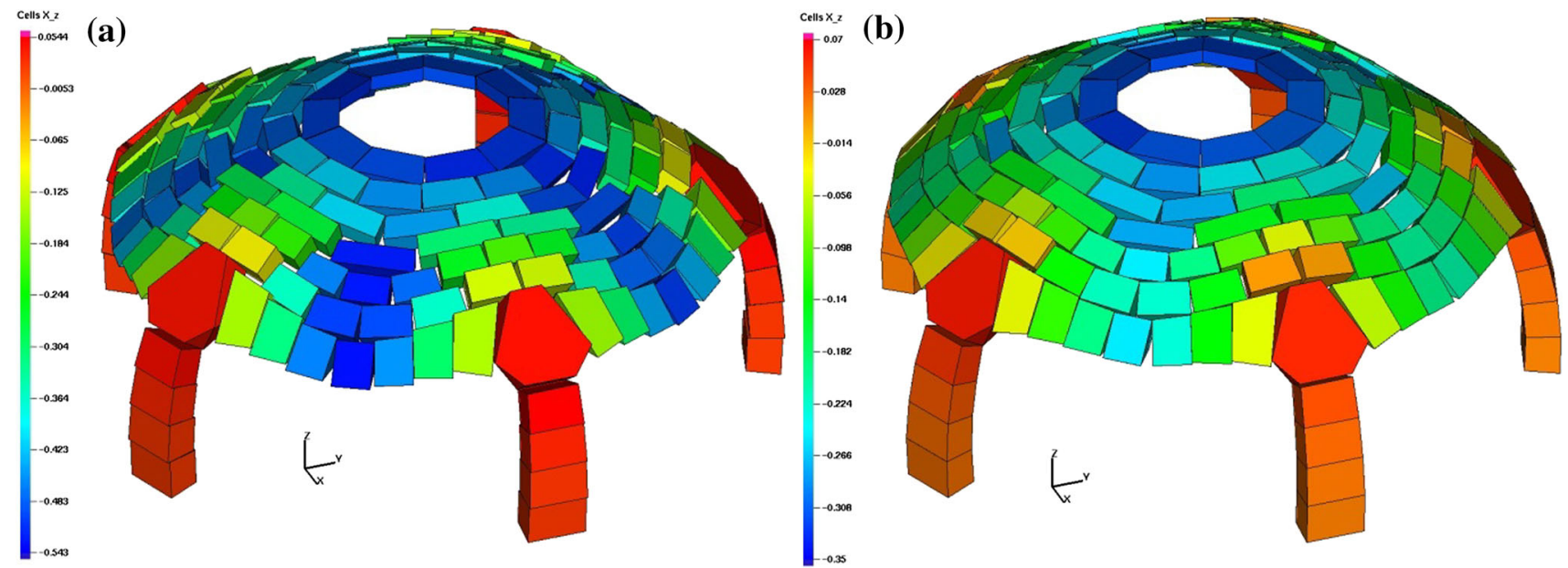

Fig. 3 Cupola with simplified geometry at 0.5 th second, a dry contact condition with friction coefficient of 0.7 between blocks and 0.9 between blocks and the ground, $\mathbf{b}$ state of cupola with cohesive contact (normal cohesion $1 \mathrm{kPa}$ and tangential one considered $0.7 \mathrm{kPa}$ ) 

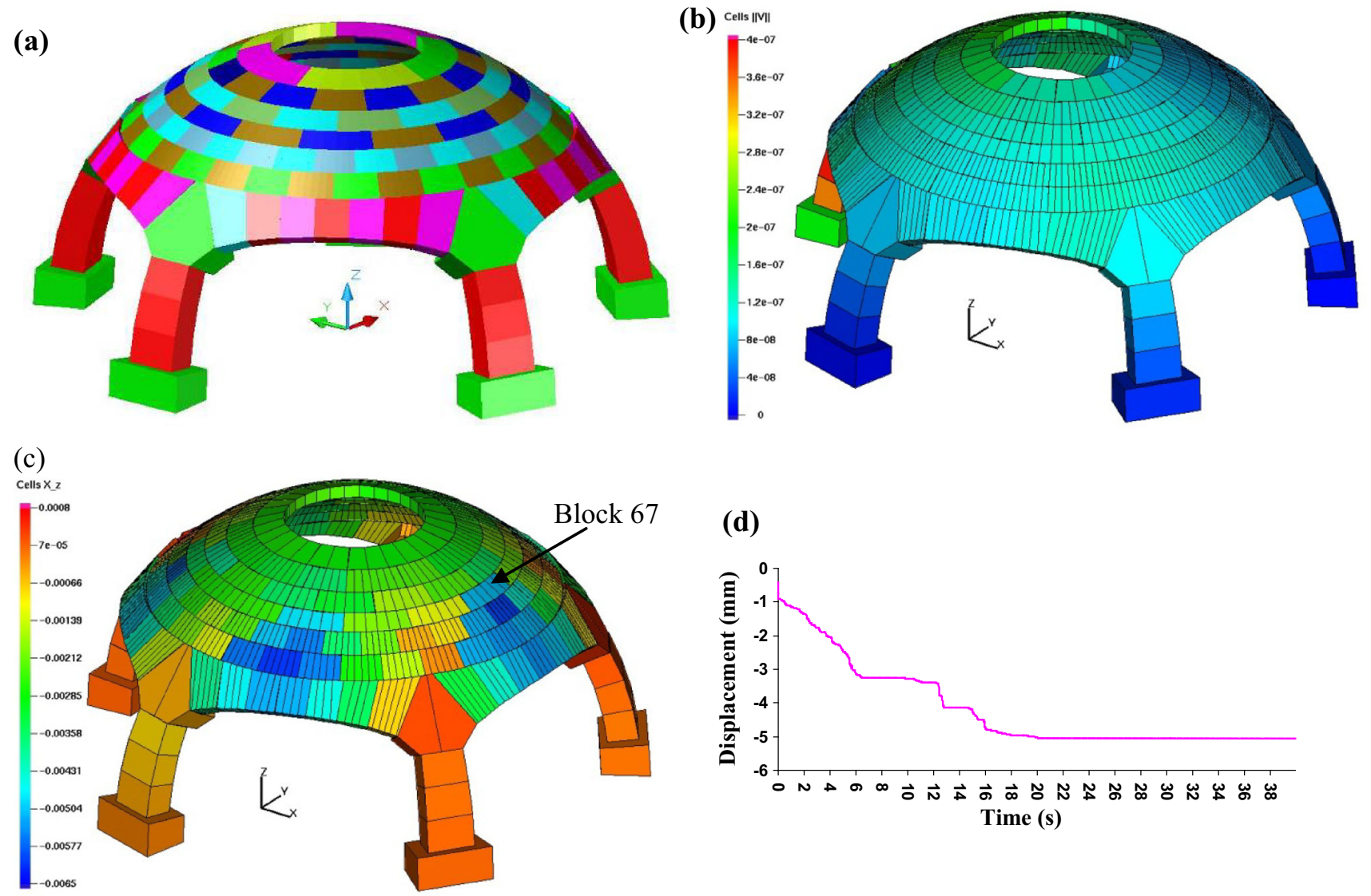

Fig. 4 Cupola of Junas with improved geometry, a geometry of the dome created on Auto CAD, $\mathbf{b}$ the magnitude of the overall velocity $(\mathrm{m} / \mathrm{s})$ for the coefficient of friction 0.7 between blocks and 0.9 between blocks and ground at 40th second, $\mathbf{c}$ vertical displacements

contacts between blocks into point-face or edge-face contacts. Figure $2 b$ shows a close-up image of the simplified model. This must be clearly stated that the current study does not in any way intended to undermine the previous studies and aims to present the necessary geometrical reforms that could be taken into account in numerical modelling to obtain more realistic results.

The behaviour of this coarse model was also investigated considering cohesive frictional contact between the blocks. The joint is cohesive until the stress vector reaches a Mohr-Coulomb fracture surface. Once broken the previous frictional contact law describes the joint behaviour. The normal and tangential cohesion thresholds for these models are, respectively, $\quad$ cohn $=1 \mathrm{MPa}$ and coht $=0.7 \mathrm{MPa}$, and the Mohr-Coulomb's cone has an opening angle $\varphi$ so that $\tan (\varphi)=\mathrm{coht} / \mathrm{cohn}$. Once a cohesive contact is broken, the contact will behave as a dry friction contact with two static and dynamic friction coefficients (respectively, in this model 0.7 and 0.6). Figure $3 \mathrm{~b}$ presents the result obtained with a cohesive contact condition at $0.5 \mathrm{~s}$ of calculation. As can be seen in this

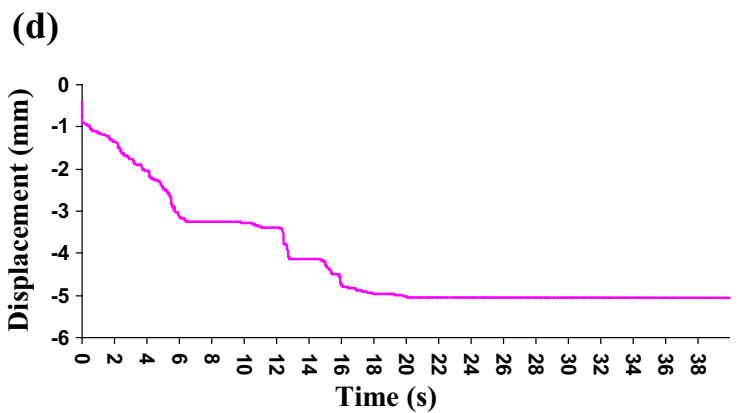

(in metre) for the same conditions, $\mathbf{d}$ Vertical displacement evolution (in millimetre) during first $40 \mathrm{~s}$ of the calculation observed for the 67 th block indicated in Fig. 4c

figure, even with a cohesive law, the structure cannot remain stable under its own weight. Falsified conditions of contacts between blocks give an inappropriate distribution of the weight distribution over the structure, resulting in a high concentration of forces in the central parts of the five arches. Consequently, the failure of the cupola begins from the arch central blocks where the load concentration caused by the upper blocks pushes these blocks towards the outside of the structure (Fig. 3). Please remember that in all the models presented in this paper, the stone blocks are considered as rigid elements.

\section{Study Using a more Realistic Geometry of the Cupola}

During a second phase of our study, the non-convex shape of blocks is approximated using a set of convex sub-blocks. Figure 4a shows the geometry used for the geometrical discretisation of the cupola, for a given colour a block subdivision is represented. This trick, despite the fact that 

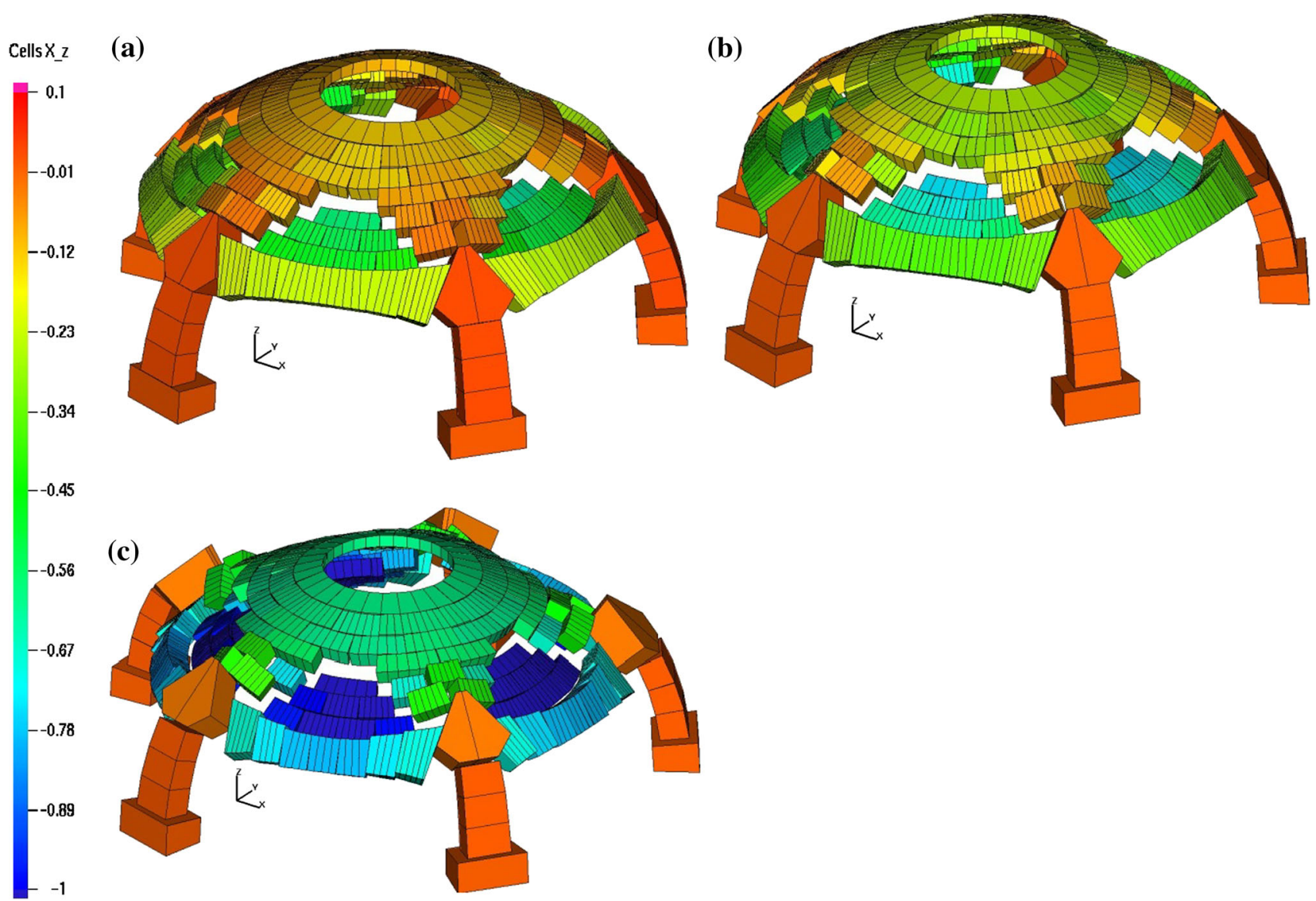

Fig. 5 Failure mechanism for the cupola of Junas for three different contact conditions, vertical displacement in metre at $0.5 \mathrm{~s}$, a model with friction coefficient of 0.3 between blocks and 0.7 between blocks

and the foundation, $\mathbf{b}$ friction coefficient of 0.3 at all contact points, c friction coefficient of 0.1 at all contact points

is a very time consuming process, enables to take into account a complex shape block considering it as a set of convex blocks.

The cupola with this improved geometry is then investigated under static and dynamic loads. In a first step, the mechanical behaviour of the structure is studied, considering only dry friction (equal to 0.7 between the blocks and 0.9 between the blocks and the ground). It should be mentioned that between blocks in the cupola structure, there is no cohesive mortar and to avoid any stress concentration the stone powder is used as filling material. In this way, the contacts between the blocks become almost planar contact and the load distribution is homogenous inside the cupola structure. The results are illustrated in Fig. 4 b, c. observing the magnitude of the velocity (Fig. 4b), under gravity alone, one sees that the structure is completely stable for these friction coefficients. Figure 4c, observing the vertical displacement of the structure (in metre) one sees that it reaches a maximum of approximately $8.5 \mathrm{~mm}$. This vertical displacement is largely due to the distance previously considered between the blocks to

prevent likely interpenetration between blocks in the model itself. The vertical displacement happens before the model reaches its primary stability. Figure $4 \mathrm{~d}$ shows the evolution of the vertical displacement (in millimetre) for the block indicated in Fig. 4c. From this graph, it can be inferred that this block, after about $5 \mathrm{~mm}$ of vertical displacement during the stabilization phase, remains stable.

To investigate possible failure mechanisms, three sets of friction coefficient were investigated. For the first model, the friction coefficient is considered to be 0.3 between the blocks and 0.7 between the blocks and the foundation. As can be observed in Fig. 5a (at $0.5 \mathrm{~s}$ ), the failure begins in all five openings with the same symmetrical mechanism. A second model consists in considering a friction coefficient of 0.3 between the blocks and the foundation. At $0.5 \mathrm{~s}$, the failure mechanism is the same (Fig. 5b), but in this model the vertical displacements are bigger than it was the case for the model shown in Fig. 5a. The first displacements occur at the level of the contact points between the five basic blocks and the ground: a sliding phenomenon appears at the level of the foundations. 
Fig. 6 Distribution of earthquakes happened in France from 1900 until 2010 with magnitude greater than 2 on the Richter scale, http://www. seisme.prd.fr/ (BCSF)

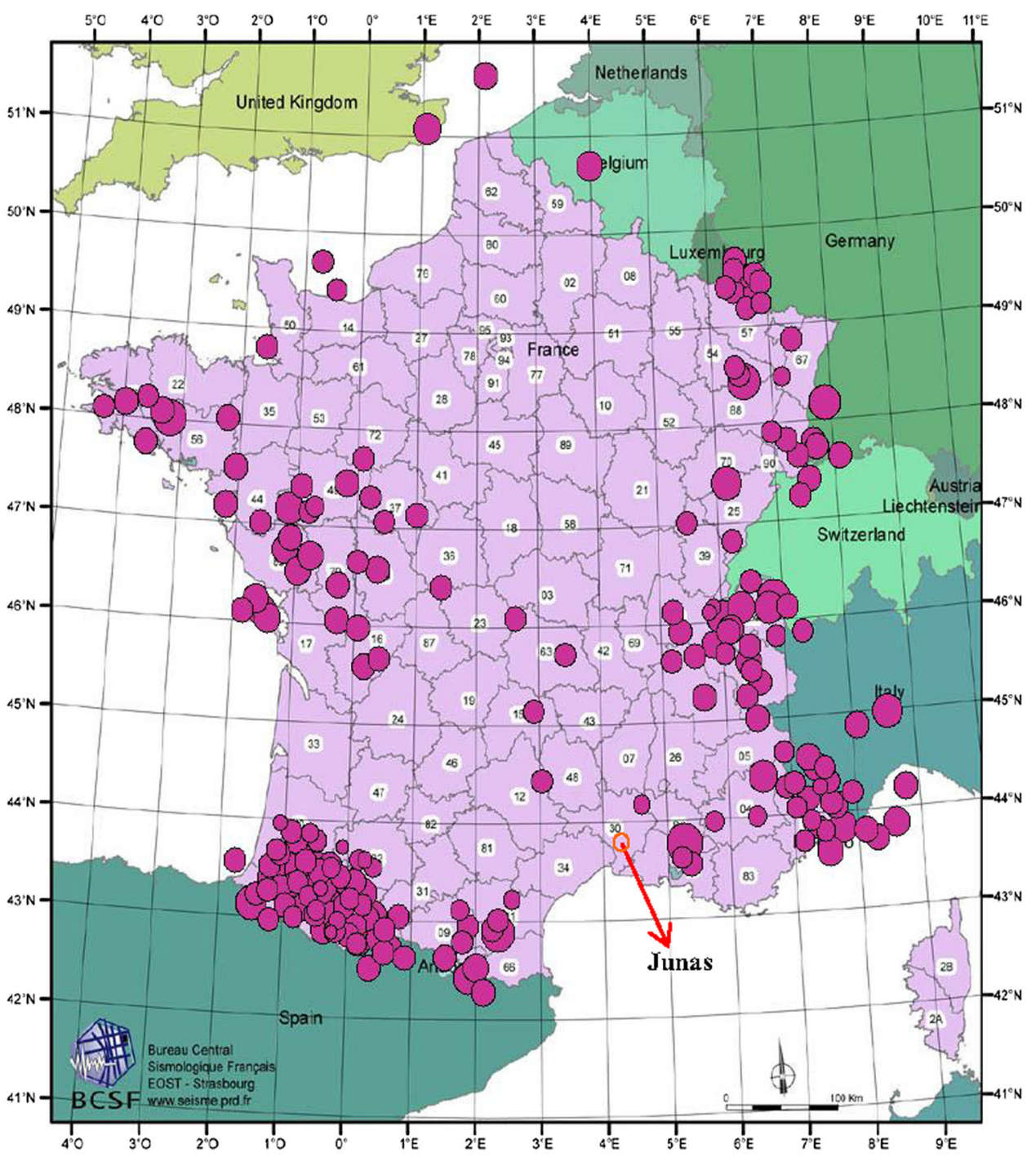

In the third model, the contact condition is considered to be deteriorated with a value of 0.1 for the friction coefficient for all the structure (Fig. 5c). As can be expected, the structure collapse occurs more quickly, since in this condition the sliding at the level of the foundation and the inner structure weakness act simultaneously. It should be mentioned that these deteriorated conditions should never happen during the cupola life.

\section{Earthquake Excitation of the Cupola with a Realistic Geometry}

Over the past 100 years, at least 38 earthquakes have caused significant damage to buildings within metropolitan France, the most hazardous areas being the Pyrenees, the Alps, Provence and the region bordering the Rhine valley [22]. Figure 6 shows the distribution of earthquakes in
France from 1900 until 2010 with a magnitude greater than 2 on the Richter scale. The location of Junas is also indicated on this map ("Bureau Central Sismologique Français" [23]).

Therefore, the dynamical behaviour of this structure is investigated, considering the seismicity of the construction area in the south-east of France. For this purpose, the accelerogram of a real earthquake with a maximum absolute value of horizontal acceleration of $0.17 \mathrm{~g}$ is applied. This earthquake happened in the Umbria and Marche regions in the centre of Italy. The seismic data used in this study were recorded at the Nocera Umbra station, located $10 \mathrm{~km}$ from the epicentre of the earthquake that occurred on April 5, 1998. This earthquake has an adequate intensity for the southern region of France. The graphs in Fig. 7 illustrate the recorded accelerations in the three directions; these graphs are used to shake the supporting element of the model simultaneously in the three directions. The 

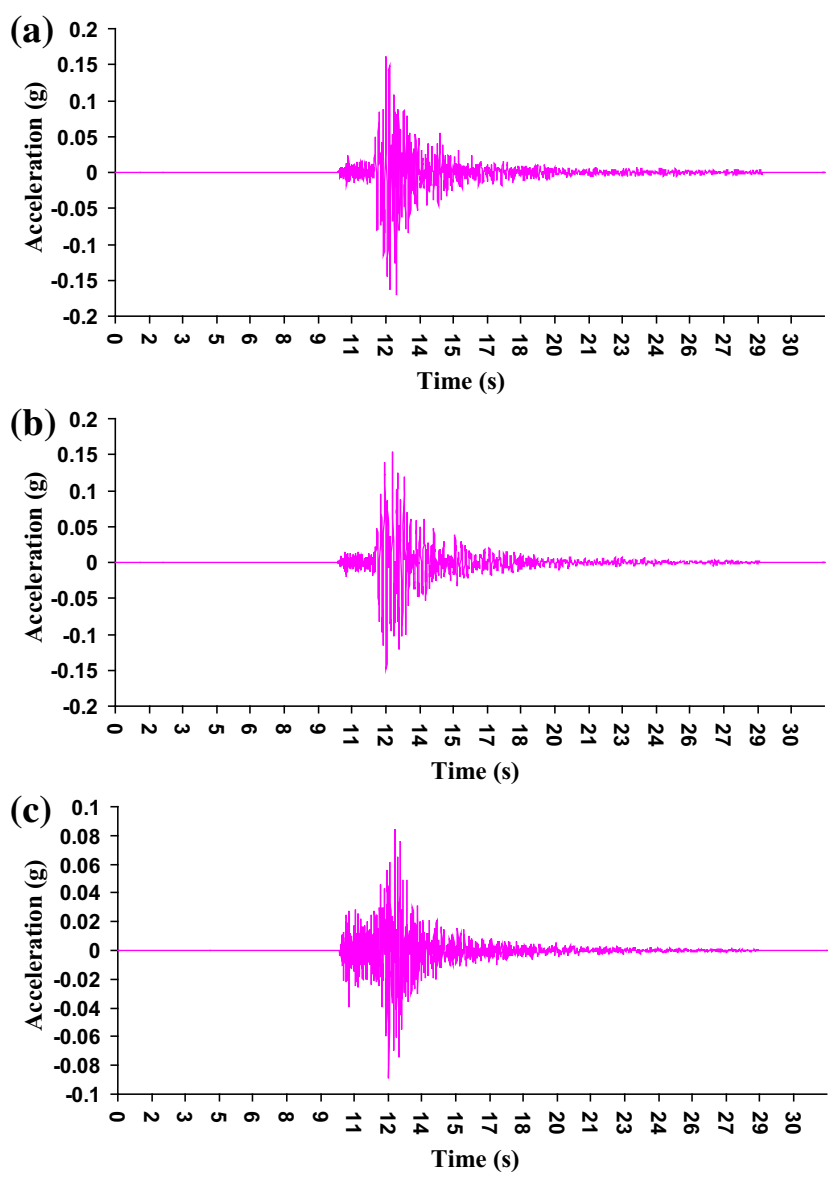

Fig. 7 Accelerogram a, b, and $\mathbf{c}$ ground acceleration in (g) respectively for the $X(\mathrm{~N}-\mathrm{S}), Y(\mathrm{E}-\mathrm{W})$ and vertical directions, recorded at the Nocera Umbra station, located $10 \mathrm{~km}$ from the epicentre of the earthquake in the Umbria and Marche regions, in the centre of Italy, that occurred on April 5, 1998

earthquake data is recorded for $31.44 \mathrm{~s}$, and after this interval, the velocity of the supporting element in all directions is considered equal to zero.

The results obtained for the model after the seismic excitation in three directions during $40 \mathrm{~s}$ are shown in Fig. 8. The Fig. 8a illustrates the state of the cupola after the seismic excitation by showing the distribution of the magnitude of the overall velocity. As can be observed in this figure, the structure has enough strength to resist against this moderate earthquake. It can be concluded that the cupola remains in a stable condition during and after this seismic excitation. These results are obtained for the dry friction contact condition with a friction coefficient of 0.7 between the blocks, and of 0.9 for the contacts between the blocks and the ground. The other graphs in Fig. 8 illustrate the velocity changes for the supporting element of the model which are recorded during the calculation. It can be observed from these two graphs recorded for $\mathrm{X}$ and $\mathrm{Z}$ direction that the velocity at the end of the seismic excitation becomes zero in all directions. The maximum of velocity for the supporting element are, respectively, $4 \mathrm{~cm} /$ $\mathrm{s}$. The horizontal velocity generated by this seism is about twice the vertical velocity. The practical data such as the velocity change can be recorded during the calculation for all bodies in the model. Because of the dry contact condition there are block displacements inside the structure during the dynamic excitation, so block separations can be observed. This block movement during the seismic excitation is governed by the dry friction contact condition (once the seismic excitation has ended, the structure regains its stable state).

During the second phase of the dynamic loading, the structure is subjected to the seism with several times the accelerations of the seism presented in Fig. 7. The contact condition considered for these models is the same dry friction contact condition for the model subjected to the real earthquake (Fig. 8). The results obtained for the seism having an intensity of 2.5 and 5 times the real seism intensity are illustrated in Fig. 9. These images show the vertical displacement caused by this "stronger" earthquake over the cupola structure. As can be observed, the structure does not completely collapse, but obvious openings can be seen inside the structure.

In the next and final step, the structure is subjected to the seism with 7.5 times the acceleration shown in the Fig. 7. The results obtained for this condition can be observed in Fig. 10. These snapshots show the possible state of the structure during a really strong earthquake. As can be seen, after $15 \mathrm{~s}$ of the excitation the structure is completely ruined (Fig. 10c). The destruction of the cupola begins from the middle of the opening arches and then spreads over the inner part of the structure (Fig. 10a, b). Figure 10d shows the evolution of the kinetic energy (in kilo Joule) generated during the seismic excitation. As can be seen, between 12 and $15 \mathrm{~s}$ of the earthquake excitation, high fluctuations of the kinetic energy are generated inside the structure. These changes correspond to high values of the seismic acceleration during this period (see in Fig. 7). The kinetic energy evolutions are negligible, before the instability condition and after of the complete collapse.

Changes in the number of active contacts during the period of calculation within the model are used to detect instability caused by the seismic excitation. Figure 11a shows the comparative graph for the number of contacts for two models subjected to the real seism and the artificial seism with 7.5 times the acceleration of the real earthquake. As can be seen, the number of the contacts during the real seism excitation remains between 4000 and 4500 points and there are not intense changes. This shows a relative stability inside this model, while for the model subjected to the excitation with 7.5 times the real seism acceleration, sudden changes can be observed, especially 


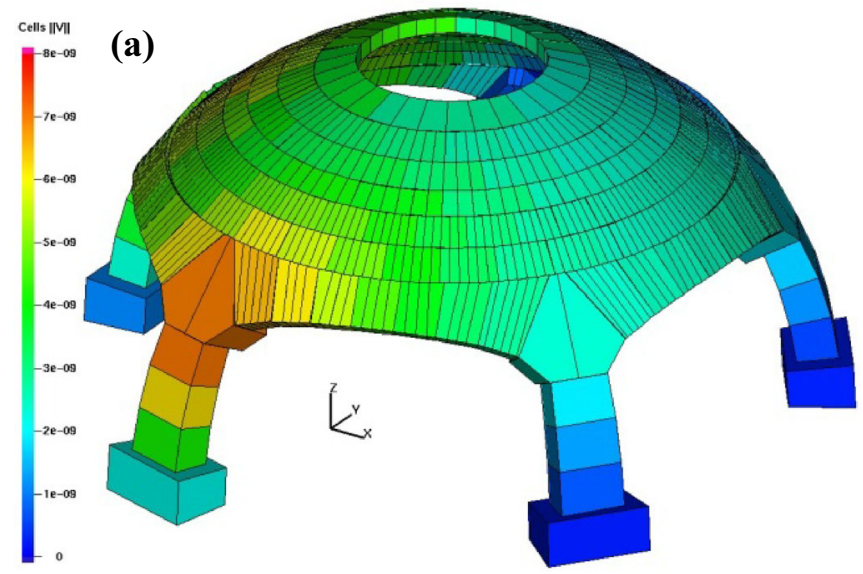

(b)

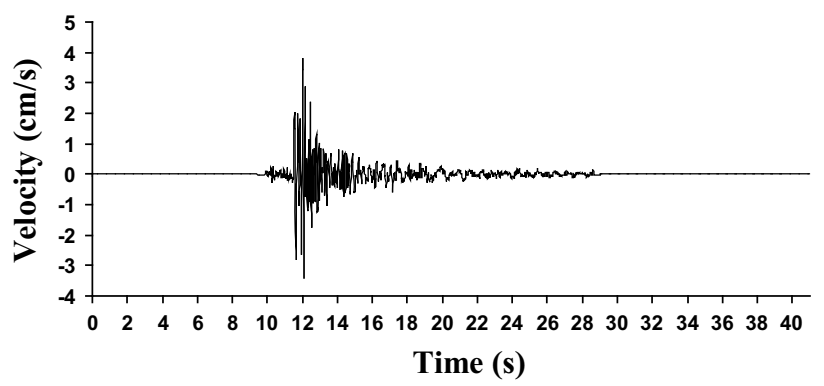

(c)

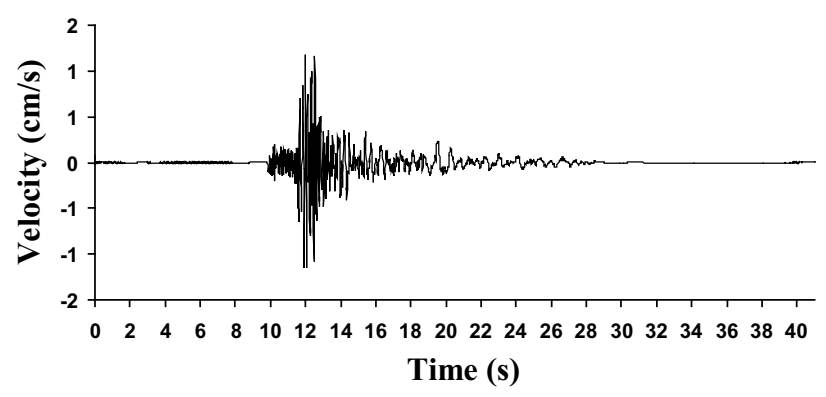

Fig. 8 a Distribution of the magnitude of the overall velocity $(\mathrm{m} / \mathrm{s})$ over the cupola structure after $40 \mathrm{~s}$ of the seismic excitation by the real accelerograms shown in Fig. 7, b, c the velocity changes $(\mathrm{cm} / \mathrm{s})$,

respectively, in the directions of $X$ and $Z$ for the supporting element of the model obtained by the data recorded during the calculation
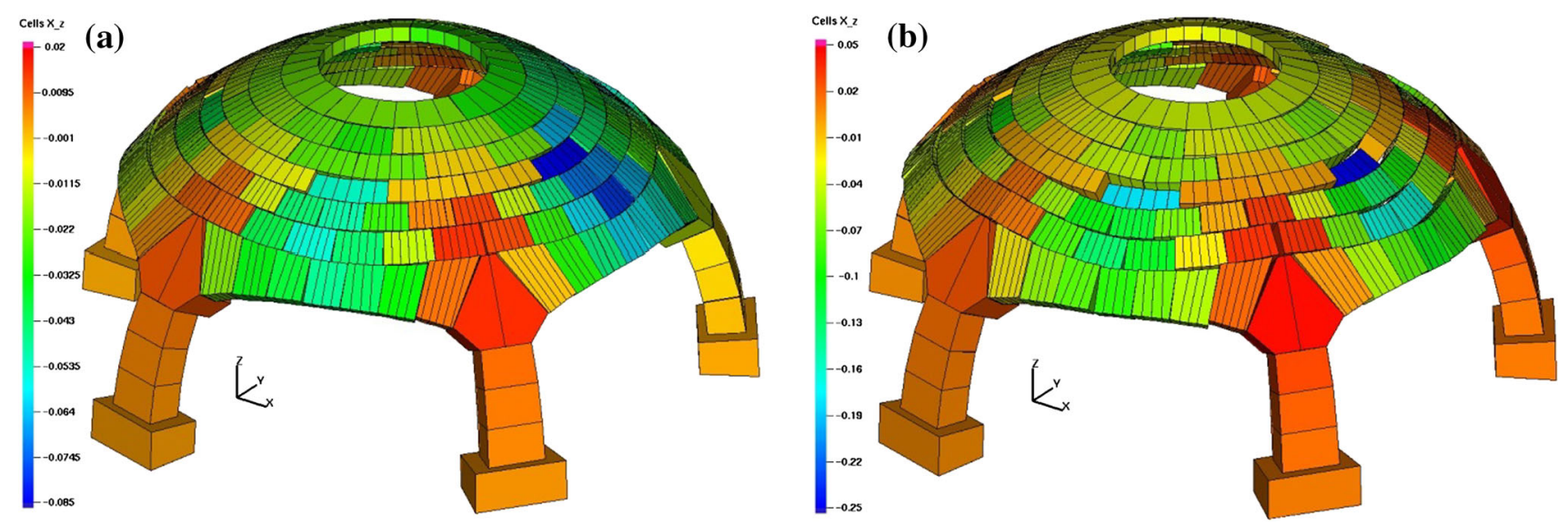

Fig. 9 Distribution of the vertical displacement (m) of the cupola structure at $40 \mathrm{~s}$, respectively, the seismic excitations are 2.5 (a) and 5 times (b) the real accelerations shown in Fig. 7

around $12 \mathrm{~s}$ during which the model loses around half of its active contacts. The vertical displacement changes of the block 67 (indicated Fig. 10a) caused by two seismic excitations with 5 and 7.5 times the real seism acceleration are illustrated in Fig. 11b. The vertical displacement of this block as a control block is also compared with the displacement of the foundation element during the seismic excitation with 7.5 times the real earthquake acceleration. This block is chosen due to its important role as a trigger of the instability of the cupola, in other words this block is a key block. In the case of the seism with 5 times the real seism acceleration, the block shows nearly $24 \mathrm{~cm}$ of vertical displacement, but it is not detached from the cupola roof as can be seen in Fig. 9b. In other words, the movement of adjacent blocks has an accumulative displacement effect on this block, and therefore, it becomes the first detached block. It should be mentioned that this issue can be observed for all five parts of the cupola. 

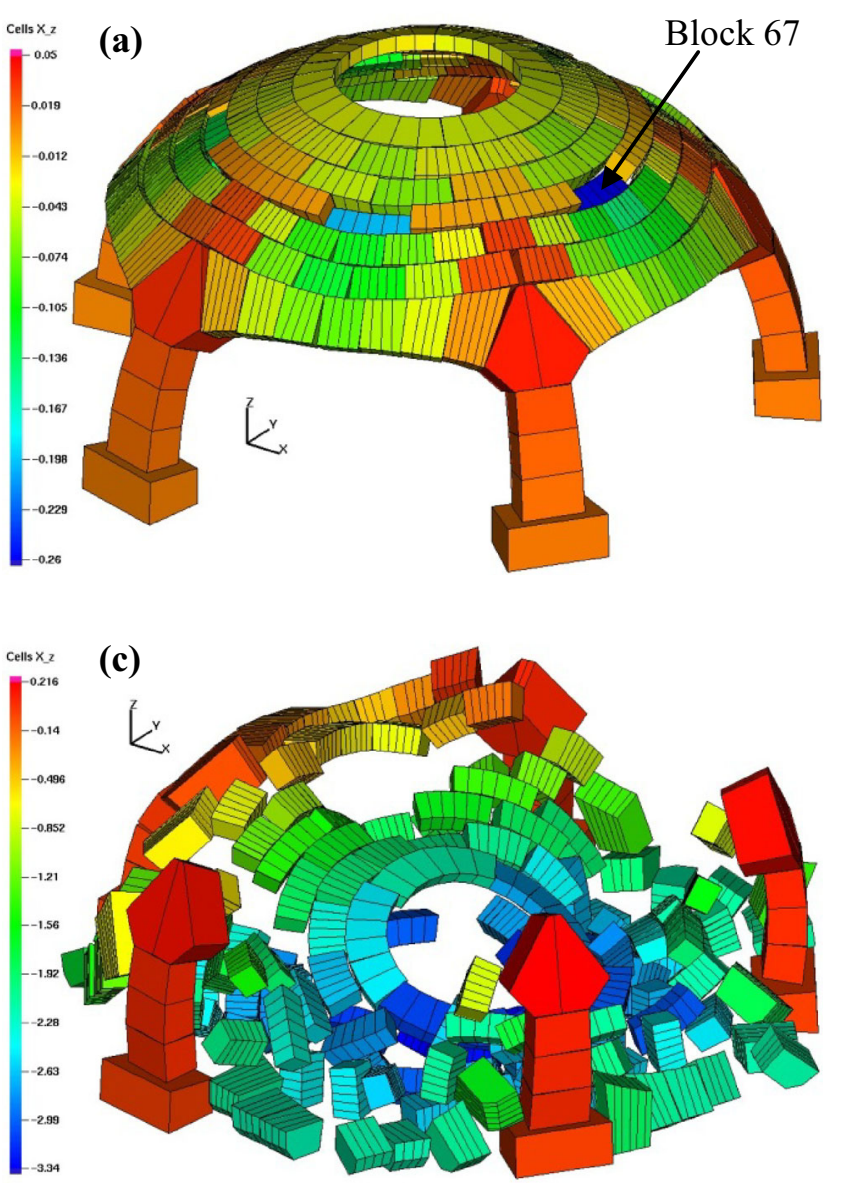

Fig. 10 a, b, and c Distribution of the vertical displacement (in metre) over the cupola structure, respectively, at 13,14 and 15th second of the seismic excitation with 7.5 times the real seismic

The stability state of the cupola is also investigated by considering cohesive contact condition under seismic loading. The cohesive condition can be assumed in the presence of mortar between blocks. The Mohr-Coulomb cohesive contact law is applied in which the normal and tangential cohesion thresholds for this model are, respectively, 0.1 and $0.07 \mathrm{MPa}$ (ten times lower than in Sect. 4) with a Mohr-Coulomb cone equal to the cone defined in Sect. 4. The cupola with this contact condition is then subjected to the intense seismic excitation with 7.5 times the real seism acceleration. The results obtained for this condition are shown in Fig. 12. As can be seen, the stability state of the model is very similar to the cupola state with dry contact condition but subjected to the seism with 5 times the real seism acceleration. Improving the contact condition at this level can strengthen the structure to resist against very intense earthquakes. In fact, the parameters used for this model were adjusted to have approximately similar results obtained for one of the model with the dry friction contact condition. Figure $12 \mathrm{c}$ shows the
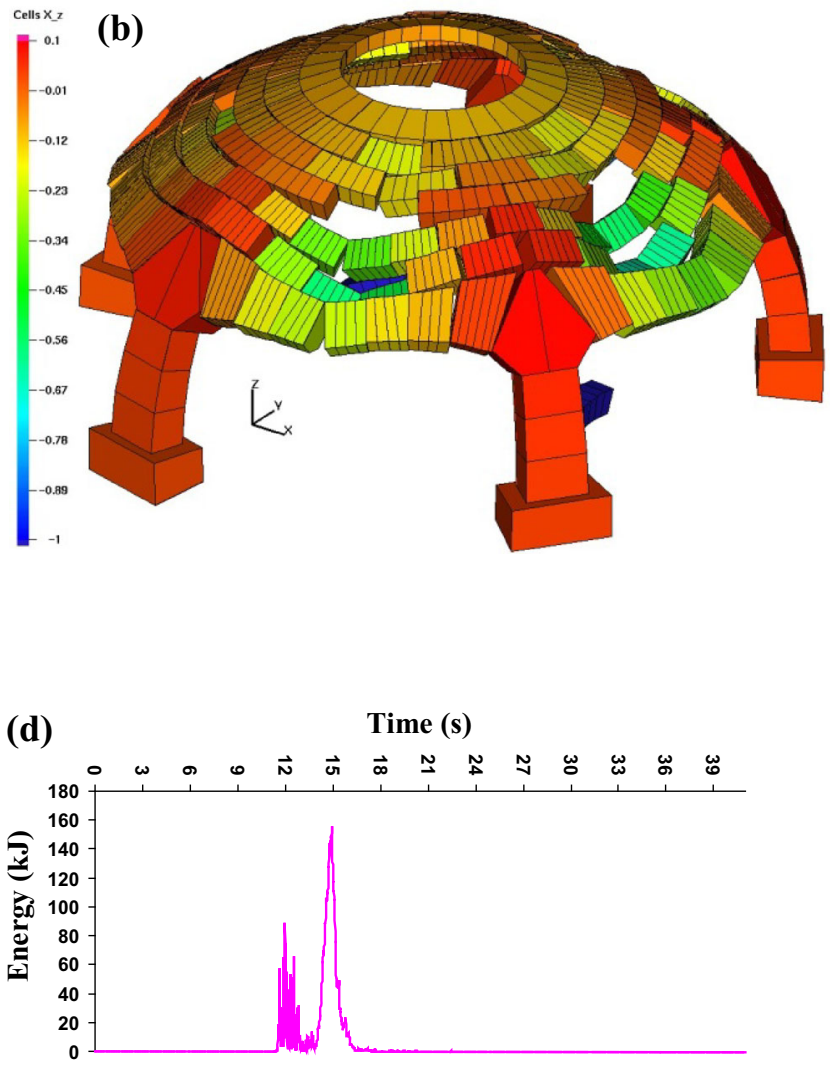

accelerations shown in Fig. 7, $\mathbf{d}$ evolution of the kinetic energy (in kilo Joule) during computation time

cumulative dissipated energy (in Joule). The dissipated energies include the consumed energy at the block contacts by the friction, shock and breaking of cohesive contacts. As can be observed, the dissipated energy is high during the strong seismic excitation and once the vibration is losing intensity, the cumulative dissipated energy becomes virtually unchanged.

\section{Conclusion}

Several different methods are used to analyse masonry structures, such as the studies referred above and also the works presented in [24-26]. This study presents a detailed investigation of the stability state of a masonry cupola under static and dynamic loads using the non-smooth contact dynamics numerical method. The NSCD method is incorporated in the LMGC90 software which was used for the current study. A series of numerical analyses was carried out by considering the effect of a simplified and a 
(a)
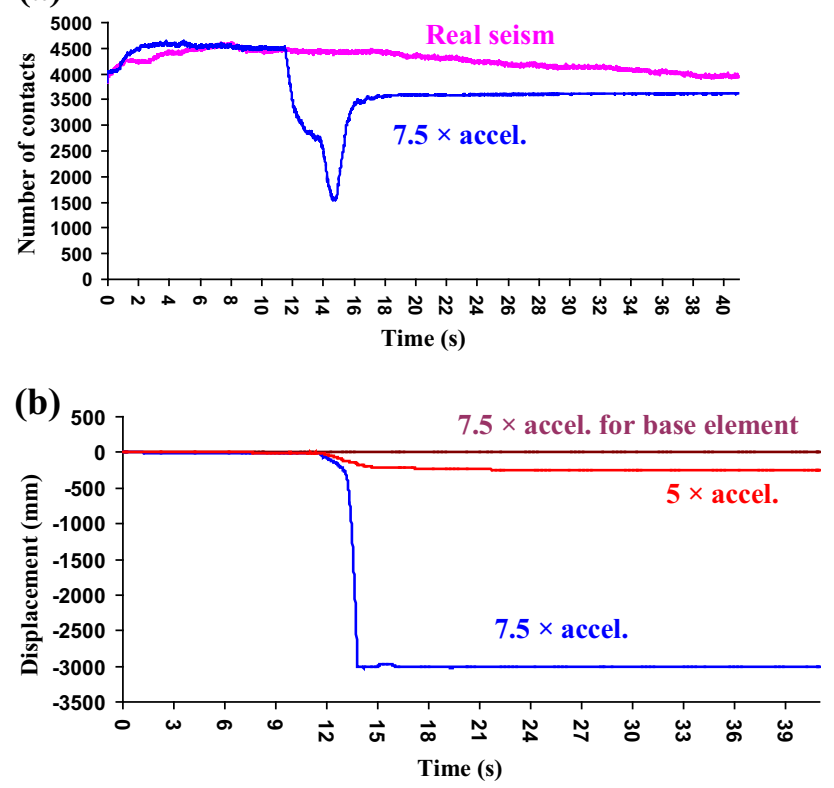

Fig. 11 a Comparative graph for the evolution of the number of active contacts during calculation for the two models subjected to the real seism and 7.5 times the real acceleration, $\mathbf{b}$ vertical displacement (in $\mathrm{mm}$ ) observed for the 67th block of the cupola indicated in Fig. 10a, caused by 7.5 and 5 times the seismic acceleration presented in Fig. 7, in comparison of the vertical displacement of the base element of the model by the 7.5 times the seismic acceleration

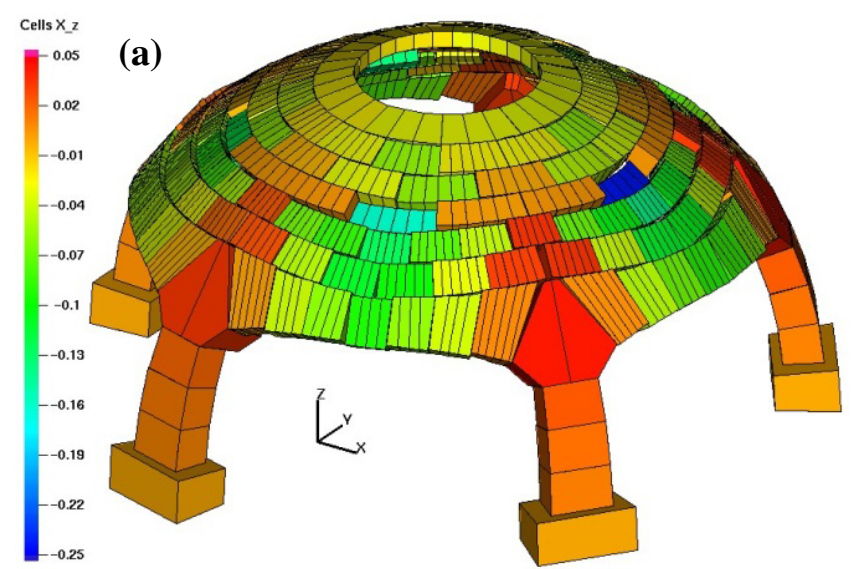

(c)

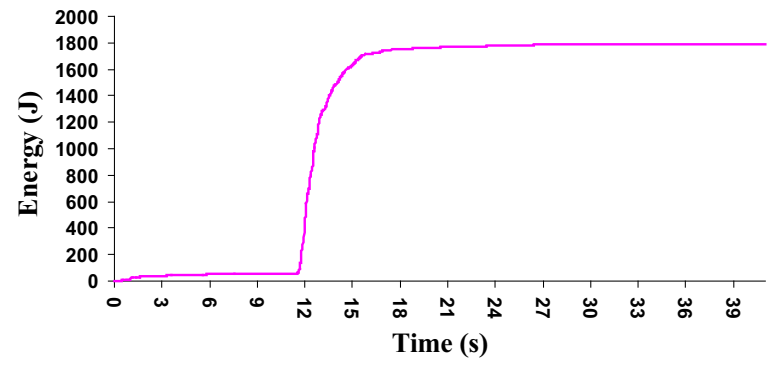

Fig. 12 Cupola with cohesive contact condition subjected to the seismic acceleration of 7.5 times of the accelerogram shown in Fig. 7 , a distribution of the vertical displacement (in metre) over the cupola realistic geometry on the mechanical behaviour of the masonry cupola under different loading conditions. The critical impact of a realistic geometry on the correct distribution of the weight load over the structure stability was investigated. It was shown that a simplified geometry can concentrate, in erroneous ways, the structure own weight forces at key points, and that the structure becomes instable even when considering strong cohesive contact conditions. Taking into account the non-convex shape of a block as a set of convex blocks helps to overcome stability problems generated by the geometrical simplification. It should be noted that, for greater safety caution, pre-stressed cables are used inside the constructed dome.

In a second phase of the study, the stability state of the geometrically well modelled cupola was checked with different contact conditions to show realistic results obtained by the numerical modelling and to examine different collapse mechanisms caused by the change of contact parameters.

Finally, the real 3D geometry of the Junas cupola is studied by numerical modelling under seismic loads with different levels of intensity. To demonstrate the computing capability of the NSCD method, on which the free LMGC90 software is based. It should be added that various contact laws with different parameters in dynamic loading condition were also used.

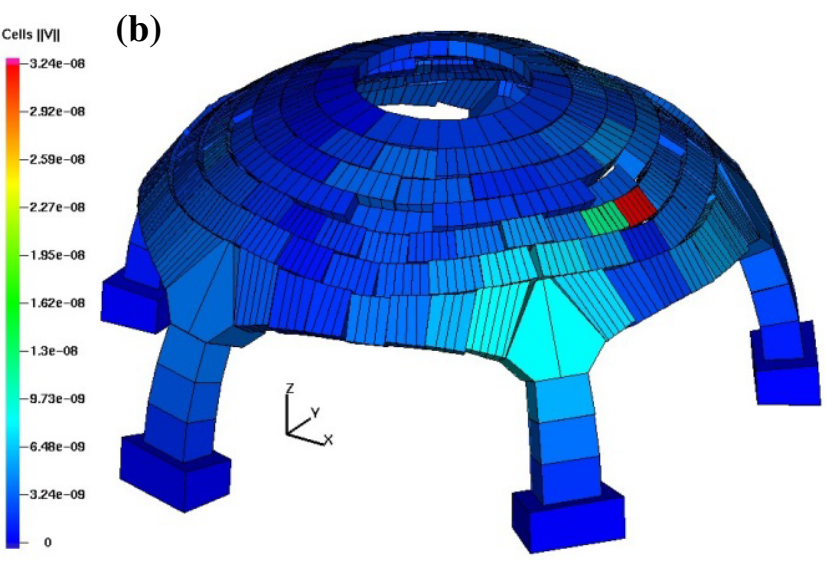

structure (40th second), $\mathbf{b}$ distribution of the magnitude of the overall velocity $(\mathrm{m} / \mathrm{s})$ (40th second), $\mathbf{c}$ evolution of the cumulative dissipated energy (in Joule) during computation time 
Acknowledgements The authors are grateful to Frédéric Dubois from the Laboratoire de Mécanique et Génie Civil de Montpellier, France, for his valuable remarks on the NSCD method and especially on the LMGC90 code. The authors would also like to thank Etienne Bertrand from the "Laboratoire Régional des Ponts et Chaussées de Nice" for providing the recorded data of the earthquake.

\section{References}

1. Rafiee A, Vinches M (2013) Mechanical behaviour of a stone masonry bridge assessed using an implicit discrete element method. Eng Struct 48:739-749

2. Idris J, Verdel T, Al-Heib M (2007) Numerical modelling and mechanical behaviour analysis of ancient tunnel masonry structures. Tunn Undergr Space Technol 23:251-263

3. Dubois F, Jean M (2003) LMGC90 une plateforme de développement dédiée à la modélisation des problèmes d'interaction. In: Actes du sixième colloque national en calcul des structures. CSMA-AFM-LMS, 111-118

4. Moreau JJ (1993) New computation methods in granular dynamics. Powders and Grains 93. A.A. Balkema, Rotterdam, pp 227-232

5. Moreau JJ (1998) Unilateral contact and dry friction in finite freedom dynamics, Volume 302 of International Centre for Mechanical Sciences, Courses and Lectures. Springer, Vienna, $1-82$

6. Moreau JJ (2004) An introduction to unilateral dynamics. In: Frémond M, Maceri F (eds) Novel Approaches in Civil Engineering, Number 14 in Lecture Notes in Applied and Computational Mechanics. Springer-Verlag, New York, 1-46

7. Jean M (1988). Unilateral contact and dry friction: time and space variables discretization. Arch Mech Warszawa 40(1):677-691

8. Jean M (1995) Frictional contact in rigid or deformable bodies: numerical simulation of geomaterials. Elsevier Science Publisher, Amsterdam, pp 463-486

9. Jean M (1999) The non-smooth contact dynamics method. In: Special issue on modelling contact and friction. Comp Methods Appl Mech Eng 177:235-257

10. Jean M (2001) Micromécanique des matériaux granulaires, chapter Simulation numérique discrète, Editor Hermes, Paris, 199-324

11. Jean M, Moreau JJ (1992) Unilaterality and dry friction in the dynamics of rigid body collections. Proceedings of contact mechanics international symposium. Presses Polytechniques et Universitaires Romandes, Lausanne, pp 31-48
12. Radjai F, Richefeu V (2009) Contact dynamics as a nonsmooth discrete element method. Mech Mater 41:715-728

13. Renouf M, Dubois F, Alart P (2004) A parallel version of the non-smooth contact dynamics algorithm applied to the simulation of granular media. J Comput Appl Math 168(1-2):375-382

14. Acary V, Blaise JY, Drap P, Florenzano M, Garrec S, Jean M, Merad D (1999) NSCD method applied to mechanical simulation of masonry in historical buildings using MOMA. In: XVII CIPA (International Committee for Architectural Photogrammetry) International Symposium WG3-Simple methods for architectural photogrammetry. Olinda, Brazil

15. Rafiee A, Vinches M, Bohatier C (2008) Application of the NSCD method to analyse the dynamic behaviour of stone arched structures. Internat J Solids Structures 45:6269-6283

16. Rafiee A, Vinches M, Bohatier C (2008) Modelling and analysis of the Nimes arena and the Arles aqueduct subjected to a seismic loading, using the non-smooth contact dynamics method. Eng Struct 30:3457-3467

17. Cundall P (1971) A computer model for simulating progressive large scale movements of blocky rock systems. Proc Symp Int Soc Rock Mech 1:132-150

18. Cundall PA, Strack ODL (1979) A discrete numerical model for granular assemblies. Géotechnique 29(1):47-65

19. Topin V, Dubois F, Monerie Y, Perales F, Wachs A (2011) Micro-rheology of dense particulate flows: application to immersed avalanches. J Non-Newtonian Fluid Mech 166:63-72

20. Chetouane B (2004) Approche combinée éléments finis/éléments discrets pour la modélisation des structures maçonnées. PhD. thesis, Université Montpellier II, France, p 245

21. Perales R (2007) Modélisation du comportement mécanique par éléments discrets des ouvrages maçonnés tridimensionnels. Contribution à la définition d'éléments de contacts surfaciques. $\mathrm{PhD}$ thesis, University of Montpellier II, France, p 241

22. Douglas J (2006) Difficulties in predicting earthquake ground motions in metropolitan France and possible ways forward. Géosciences 4:26-31

23. Bureau Central Sismologique Français (2013) Ecole et Observatoire des Sciences de la Terre. http://www.seisme.prd.fr/. Accessed 25 June 2013

24. Ghanbari A, Hoomaan E, Mojallal M (2013) An analytical method for calculating the natural frequency of retaining walls. Int J Civil Eng Trans B Geotech Eng 11(1):1-9

25. Palmisano F, Elia A (2014) Assessment of masonry buildings subjected to landslide by using the load path method. Int J Civil Eng Trans A Civil Eng 12(2):312-330

26. Tootoonchy F, Asgarian B, Danesh F (2015) Experimental inplane behavior and retrofitting method of mud-brick walls. Int $\mathrm{J}$ Civil Eng Trans A Civil Eng 13(2):191-201 